\title{
Students' Perceptions of Debating as a Learning Strategy: A Qualitative
}

\section{Study}

\section{Abstract}

Debate has been shown to develop critical thinking skills, enhance communication, and encourage teamwork in a range of different disciplines, including nursing. The objective of this study was to explore students' perceptions of the educational value of debate. A semi-structured focus group was conducted with 13 undergraduate Operating Department Practice students following a debate on the opt-out system of organ donation. Transcripts were analysed thematically, identifying three main themes that described the students' perceptions of the debate. These were: (1) openness to diverse viewpoints; (2) developing non-technical skills, and (3) encouraging deep learning. The analysis showed participants perceived debate to be a valuable educational method that enhanced their learning. Engaging in debate encouraged students to critically reflect on their prior beliefs about organ donation - in some cases leading them to reconsider their original position. The findings from this study suggest that debate can be a valuable pedagogical tool to incorporate into healthcare education. Future research should consider the use of debate to develop non-technical skills that have utility in healthcare.

\section{Keywords}

DEBATE; EDUCATION; QUALITATIVE; HEALTHCARE PROFESSIONALS; ORGAN DONATION 


\section{Highlights}

- Debates can encourage students to critically reflect on their ethical beliefs about controversial topics such as organ donation and encourage viewpoint diversity.

- Students perceived that debates can be a valuable means of developing non-technical skills relevant to their clinical roles.

- Preparation and participation in debates can encourage students to employ a deep approach to learning where they interpret the topic as meaningful and worthy of investing time to understand.

\section{Introduction}

In recent years, a number of serious high profile failures have shaken the public's trust in the clinical and ethical competence of those working in healthcare (Chadwick and Gallagher, 2016). One high profile example would be the systemic failings at the Mid Staffordshire NHS Trust as detailed in the inquiry led by Robert Francis (2013). The failings at the Mid Staffordshire NHS Trust may have contributed to a significant number of unnecessary patient deaths due to neglect, abuse, substandard care, and systemic clinical governance failures (Carter and Jarman, 2013). It is therefore essential that all healthcare students are equipped with the ethical, critical thinking and non-technical skills to help them navigate the complex situations they encounter when interacting with their patients, and the decisions they will have to make in practice. Therefore, pedagogical methods that encourage further development of such skills will have significant utility (Onen, 2016). 
The use of debate for educational purposes goes back thousands of years, and flourished as a pedagogical method under the Greek philosophers Protagoras of Abdera (482-411 BC) and Aristotle (384-322 BC) (Huryn, 1986). Debate allows students to actively participate in their learning and requires the use of skills that are not easily developed in a traditional didactic context (Oros, 2007). It imposes a structured approach to a topic and encourages students to take responsibility for their own learning (Snider and Schnurer, 2006). Debate requires effective teamwork that is ordered towards a shared goal—preparation for and participation in the debate (Koklanaris et al., 2008). Teamwork is an essential component of ensuring effective team performance and for maintaining patient safety (Wacker and Kolbe, 2014), and unique ways of advancing teamwork-as well as other non-technical skills—amongst healthcare students deserve further exploration.

Over the last few decades, the use of debate in the higher education classroom has grown, this is reflected in the wide range of academic disciplines that now utilise debate as part of their pedagogical toolkit, including nursing, medicine, radiography, and pharmacy (Stewart-Lord et al., 2011; Doody and Condon, 2012; Keynejad et al., 2017; Peasah and Marshall, 2017). Debates have been shown to develop critical thinking, communication, teamwork, oral presentation skills and reasoning abilities (Candela et al., 2006; Hanna et al., 2014; Arrue et al., 2017). When teaching controversial topics such as organ donation, debates may have some benefits over a traditional lecture, leading to improved information acquirement and retention (Koklanaris et al., 2008; Boucaud et al., 2013). However, these benefits may be related primarily to the preparation required for the debate rather than the debate itself. 
A debate has been described as an 'equitably structured communication event about some topic of interest, with opposing advocates alternating before a decision-making body.' (Snider and Schnurer, 2006, p.6). In this study, the debate incorporated a cross-examination element, which requires a predetermined time for an opposing side to challenge and rebut claims and assertions following an opponent's opening statement and main arguments. Debates that utilise a cross-examination element have previously been used in bioethics education for nursing students and this has been shown to positively affect ethical understanding and ethical competence (Choe et al., 2014). Ethical competence describes the knowledge, skills and attitudes needed to respond to ethical issues that can arise in the clinical setting and which may help to reduce moral distress (Schaefer and Vieira, 2015; Robichaux, 2016; Kulju, 2016). Although the purpose of this study was not to measure an increase in moral competence, the researchers anticipated that students could subsequently benefit from these positive effects.

The literature surrounding moral distress has grown extensively over the last decade, primarily in nursing but also encompassing a wide range of different healthcare professions (Brazil et al., 2010; McCarthy, 2013; Penny et al., 2014; Austin, 2017). Moral distress can be broadly understood as the psychological, emotional and physiological suffering that arises from morally challenging situations or events (McCarthy, 2013; Morley et al., 2017). Preparing healthcare students to overcome and navigate the morally challenging situations they will inevitably face in clinical practice is essential to negate and reduce the negative effects of phenomena such as moral distress (Monrouxe et al., 2015). 
Healthcare education should facilitate the development of critical thinking skills, and nurture the ability to engage in ethical reasoning that can promote the ongoing development of ethical competence. Students will inevitably encounter a range of ethical issues involving conscientious objection, informed consent, confidentiality, and end-of-life care. Furthermore, technology and medical advances are also developing at a rate that make it difficult for educators to anticipate the ethical challenges and dilemmas that healthcare professionals will face in the future. Concerns about their ability to manage these ethical challenges are arguably not unfounded.

A structured debate requires consideration of alternative viewpoints prior to arriving at a conclusion about the topic. It also involves evaluating the strengths and weaknesses of each view and critically engaging with ideas one may not have considered previously, requiring and encouraging analytical thinking (Vo and Morris, 2006; Kennedy, 2007). The promotion and development of these types of skills are essential to fairly and critically respond to the ethically and clinically challenging situations that students and all healthcare professionals might encounter. This study was conducted to evaluate the pedagogical value of a debate by exploring the perceptions of students following their preparation and participation. The themes identified from the thematic analysis provide additional support for the educational benefits that debate has been shown to have in previous studies in nursing and allied health education (Doody and Condon, 2012; Hartin et al., 2017; Peasah and Marshall, 2017).

\section{Methods}

\subsection{Participants}


The study was conducted in one UK higher education institution (HEI) that offers a 3-year BSc (Hons) degree in Operating Department Practice (ODP). ODP's are a group of registered allied health professionals in the United Kingdom who primarily work in the operating department and possess specialist knowledge and skills in the three main areas of perioperative practice: anaesthetics, surgery and recovery (Rodger and Mahoney, 2017). The participants were 13 second-year undergraduate ODP students of which $31 \%$ were male $(n=$ 4) and $69 \%$ were female $(n=9)$ out of 14 total students in the cohort undertaking the module. Ethics approval was obtained from the University Ethics Panel.

\subsection{Study Design}

Prior to the implementation of the debate, ethics education was taught explicitly by following a traditional didactic teaching format. All students in the module were provided with a participant information sheet two weeks prior to the debate, which invited them to take part in the study. Although participation in the study was voluntary, students were all expected to participate in the debate, as it comprised the formative assessment component of the module. Students who agreed to participate were then required to confirm their participation by signing a consent form. This constituted their agreement to participate in a focus group following the debate, for it to be audio-recorded, transcribed and for any findings to be disseminated via publication of the results.

Participants were informed on the first day of the module that the formative assessment would be a debate on the motion 'This house believes that England should move to an opt-out 
organ donation system'. This topic was chosen to encourage student engagement following the Government's public consultation on 'Introducing 'opt-out' consent for organ and tissue donation in England', which ran between December 2017 and March 2018 (Department of Health and Social Care, 2017). Students were then split into two randomised groups, with one group presenting the pro (for) side and the other the con (against) side of the motion. Each individual student was provided with a written guide on debate. The guide detailed the structure of the debate, introduced relevant terminology and an example of the marking rubric. The following week, students were given a lecture on the topic of debate, this included - a detailed discussion of what constitutes sound and valid arguments and examples of fallacious reasoning. Time was set aside within the lecture for students to participate in a practice debate on the topic of whether there should be an upper age limit for the provision of female fertility treatment. The additional teaching was provided to ensure that students were equipped to critically examine arguments in the ethical and philosophical literature and to understand how evidence can be employed to support opposing viewpoints. The format of the debate is described in figure 1.

\subsection{Data collection}

The philosophical approach in this study was interpretivist, allowing the researchers to gain an understanding of how students interpreted, understood, and experienced their learning (Mason, 2017). A focus group discussion was used as a qualitative approach to gain an in-depth understanding of the experiences of the students collectively. This qualitative inquiry was subjective and provided in-depth descriptions and imaginative insights into the participants views of preparing and participating in a debate for educational purposes. The 
aim of using focus groups instead of interviews was to understand the ways in which students construct their learning as a group through a naturalistic approach.

One focus group was conducted following the debate using open-ended questions to guide the discussion; participants were also encouraged to speak freely. Sufficient time was allocated to welcome participants, explain the purpose of the focus group and establish concise agreed upon ground rules, and to respond to any questions (Goodman and Evans, 2010).

The research team consisted of two faculty members, the second author being an experienced researcher who led the focus group, which lasted for 40 minutes. The interviews were recorded on a digital recorder and transcribed verbatim, which was subsequently checked by both researchers to ensure the credibility of results. The focus group allowed participants to explore their perceptions and experiences of the debate. This included: exploring how they prepared as individuals and as a member of a team; whether or not the debate helped to develop any skills; and if it had any application for their clinical practice.

\subsection{Data analysis}

Data was analysed using a thematic analysis, utilising the six phases outlined by Braun and Clarke (2006). Both researchers first listened to the audio recording and re-read the transcript several times in an attempt to immerse themselves in the data set — thereby becoming increasingly familiar with it. This also provided an opportunity to check the written transcript against the audio recording. The second phase involved identifying codes by systematically 
working through the data set: a code describes a feature within the data that can be assessed and is considered relevant to the research question and may contribute to a theme (Braun and Clarke, 2006). A theme describes a recurring pattern that captures something meaningful within the data set. In the third phase, agreed codes were then incorporated into candidate themes; codes that described a similar feature within the data set were subsequently combined. The fourth phase required reviewing the themes to ensure that they accurately reflected the data set and that each theme was distinct from the other. This required two levels of reviewing. Firstly, ensuring that the codes formed a cohesive pattern and secondly, that the themes accurately reflected the meanings found in the data set as a whole (Braun and Clarke, 2006). Analysis of the data then moved onto phase five, which entailed naming and clearly defining each identified theme; this also required determining the story that each theme communicated, and whether it reflected the overall story within the data. The final phase required providing evidence for the themes by choosing data extracts that communicated the essence of the theme and supported the analysis of the data set.

Trustworthiness of the findings was established by the researchers auditing events, exploring influence and confirming subsequent actions through regular meetings. Decision making regarding research methodology and process were agreed and recorded in these meetings. Data analysis was performed by both researchers and agreement on codes and themes was achieved independently and collectively to further ensure rigour.

\section{Results}


The thematic analysis explicated three themes that described the participants' perceptions of the debate. These were: (1) openness to diverse viewpoints; (2) developing non-technical skills, and (3) encouraging deep learning. In quotations utilised below, participants have been anonymised by replacing their names with a number to ensure confidentiality.

\subsection{Openness to diverse viewpoints}

This theme described the openness and increased willingness of the students to consider diverse viewpoints. Students were required to undertake thorough preparation in advance of the debate, providing an opportunity to immerse themselves in the topic of debate. This created an environment that actively encouraged exposure to and having to engage with ideas and arguments that they may not have previously encountered.

Exposure to diverse viewpoints facilitated an increased openness to the plausibility of views that the student themselves did not hold. This increased openness seems to have developed as a consequence of having to research both sides of the motion. Being exposed to diverse viewpoints also led students to critically reflect on their own opinions in light of their own research.

"I think I've learnt to be more open minded to other views, because I started off more on the pro side and then, with the more research I did on con, it opened my mind to other opinions." (Participant 3) 
Preparation for a debate requires exploring both the pro and con sides of the motion and students identified the need to do so. Effective preparation necessitates anticipating the arguments and counter-arguments of your opponents and how you might respond. Being open to consider the bigger picture, encompassing the nuances of the topic was an important facet of their preparation, instead of relying primarily upon their own opinions.

"It makes you look at both sides, because you need to. So what I've decided, well you need to, in the back of your mind, think what the other team is going to come up [with], what you might counteract, so it does make you look at the whole picture rather than focusing just on one thing, your own opinion." (Participant 5)

Furthermore, not only did the preparation encourage an increased openness to diverse viewpoints, but also listening to the opposing team's arguments challenged students to question their own conclusions about the topic of the debate. There was a clear appreciation for the opportunity to listen to both sides of the debate and to see value in doing so attentively.

“...but listening to other people's arguments, so yes, so maybe I'm not right, it's just nice to see two sides of the coin." (Participant 3)

\subsection{Developing non-technical skills}

Participants identified non-technical skills that they had begun to develop from the preparation and participation in the debate, in some cases connecting this to their role in 
clinical practice. Non-technical skills are 'the cognitive, social, and personal resource skills that complement technical skills, and contribute to safe and efficient task performance' (Flin et al., 2008). Students described feeling more confident in their own abilities — for instance as a leader and communicator. The development of non-technical skills has utility in the areas students hope to be employed in, following completion of their studies. This is because the safe and effective delivery of patient care is contingent upon the presence and development of non-technical skills (Agha et al., 2015).

Participants described how being a student in the clinical context can make communicating their views challenging and emphasised the fear of subsequently being confronted and having to give an account of their views. The debate provided an opportunity to engage in rational discourse in a context that could involve conflict and stress. It functioned as a space and opportunity to have their views "critiqued" and where they could communicate informed arguments in response to having their views or speech challenged. The debate became somewhere to practice and prepare for analogous situations in clinical practice. Other than in a debate there are very few educational contexts where students are required to think under pressure and to communicate ideas that may be immediately challenged by their peers - something that does happen in clinical practice.

"In clinical practice you come across so many situations where there is a conflict of interest and you want to put a point across, but because of pressure or, I don't know, from being a student and trying to speak up to people that you work with in clinical practice...it can be quite scary to put your point across and then for them to question you about it, but then 
having this debate prepares us for being critiqued on what we're saying, so we can argue back and give a rationale as to why we're saying what we're saying." (Participant 2)

The debate provided an educational context for students to develop their leadership skills, mirroring the kinds of opportunities and requirements they can encounter in practice. This experience may make them more likely to step out of their "comfort zone" in practice and to challenge the limitations they may have placed upon themselves.

“...I kind of pushed myself out of my comfort zone into kind of leadership roles, I wasn't very confident with that, but I did it anyway, so I think initiative would be something that I learnt." (Participant 4)

Students identified that participating in the debate increased their confidence in their own ability, removing some of the limitations they may have placed on themselves. It provided a unique opportunity for students to experience communicating their knowledge in a context where they perceived themselves as having an informed viewpoint. The confident demonstration of engaging in reasoned debate made students more keenly aware of what else they might be able to do in other contexts.

"I think it's definitely an increasing confidence, like you said, that you have more potential than you think you do and that you can argue a case confidently, and are happy that you know what you're talking about as well." (Participant 2) 
Preparing and participating in the debate helped to foster a sense of "community" and encouraged teamwork and cooperation. Being part of a team in the academic setting mirrored that of one in the clinical setting. It highlighted to students the saliency of teamwork and cooperation in informing and creating change.

"I think it develops a sense of community as well, because you know your opinion on it, you're not just on your own, you're not standing alone to fight for something or to debate something in clinical practice, because you kind of belong to the community, it kind of makes you more hopeful that if you do want to change something in practice it might happen because you're not the only one that thinks that way." (Participant 6)

\subsection{Encouraging deep learning}

When describing the kind of learning that the debate encouraged, participants could be described as utilising a deep approach to learning in contrast to a surface approach (Biggs and Tang, 2007). Students engaged meaningfully with the subject and the process of preparation and participation in the debate. The deep learning approach was exemplified through the use of higher-order cognitive skills. Students were required to engage in critical thinking by having to develop counter-arguments and responding to critical questions from their peers under pressure. In the cross-examination part of the debate, students were able to demonstrate their prior research and understanding of the nuances of the debate in a high-pressure context. Students thought critically about the new material they had been exposed to and used a range of sources to make informed arguments. 
"Yes, it developed the skill, developing a counter-argument on the hoof, because in public speaking, this is fine, but you ended up...there was a period where we had to... a bit of back and forth." (Participant 3)

Some students described immersing themselves in the topic through their individual research during their preparation for the debate. Students believed that this process helped them to organise and formulate their own thoughts on the topic. The information from their research and reading could then be pulled together to form the basis of the arguments they would use in the debate. This process was essential for their own mastery of the topic.

“...I actually found individual research the most useful, just getting those nuts and bolts together to form an argument, because that's how you actually can immerse yourself in a subject I think, maybe it's an old-fashioned way of doing it, but it's by just reading and just chucking yourself into it and just trying to sort it out yourself..." (Participant 11)

Participating in the debate encouraged students to think more "deeply" about the meaning of the material being debated. The process required having to pay attention to details that could inform their own counter-arguments and questions for their debate opponents. The context of the debate made students more motivated to listen and learn.

"I guess they put you out of your comfort zone, it puts you... keeps you on your toes, because it kind of forces you, not that I wouldn't have paid attention anyway, but it makes you pay extra attention into detail the counter-argument as well, especially when you think about questions and things, it gets you to think a bit more deeply..." (Participant 12) 
Students identified some of the challenges of finding themselves on the side of the debate they were less knowledgeable about. It compelled them to do more detailed research and required them to critically interact with the material and to problem-solve.

"...if you have one side that is like...everybody knows the good points for each ethical debate, like 'Oh we know this and we know the main points', but when you're put on the other side, on the opposing side, then it's a little harder, it kind of makes you have to really research and go and work on it..." (Participant 5)

\section{Discussion}

We believe this is the first study to report and analyse the use of debate in undergraduate operating department practice education, however, findings from this study are transferable to all healthcare education courses where debate could be utilised as a pedagogical tool to enhance learning. The results emerging from the thematic analysis strongly suggest that the utilisation of debate promoted the use of higher-order thinking skills such as analysis, evaluation, and synthesis identified by Bloom et al (1956). This is consistent with the findings from a range of other disciplines such as nursing and pharmacy that also identified students engaging in higher-order thinking (Doody and Condon, 2012; Hanna et al., 2014; Peasah and Marshall, 2017).

Debate frequently requires students to defend a position they do not hold and attack a position they do, and this process can help to encourage students to become more 
open-minded (Doody and Condon, 2012; Alén et al., 2015). In healthcare education an increase in openness and a willingness to engage with diverse views as demonstrated in the first theme is an integral part of caring for patients in a diverse culture and for the development of cultural competence (Seeleman, 2009). Allied health and nursing students are all expected to treat patients equally and to not discriminate based on their own personal views (Health and Care Professions Council, 2016; Nursing and Midwifery Council, 2018). Furthermore, with the student body also becoming increasingly diverse, debate provides an opportunity for students to be exposed to a variety of ethical perspectives (Willsher, 2013). The findings showed that students attached meaning and value to evidence and arguments that challenged their own opinions. This is significant because contemporary ethical and clinical issues in healthcare can be complex and confusing - further complicated by ongoing technological advances (Talbot, 2012). The nature of debate requires moving into what can be an uncomfortable intellectual space - one where ethical views can be challenged or even changed. Kennedy (2009) found that $37 \%$ of the participants in her study changed their views after participating in a debate. Debate helps students to develop informed opinions on controversial topics by exposing them to arguments and ideas that they otherwise may not have considered (Yang and Rusli, 2012). Moreover, debate encourages viewpoint diversity and discourages confirmation bias by encouraging students to research and to engage in critical analysis to understand both sides of a debate (Nickerson, 1998). Reducing confirmation bias is desirable as it can often act as a barrier to evidence-based practice and can lead healthcare professionals to discard valuable information that contradicts their initial assumptions (Lilienfeld and Lynn, 2014). 
Non-technical skills as identified within the second theme of this study findings are essential for safe and effective patient care (Rutherford et al., 2012). For instance, human error has been implicated in $80 \%$ of adverse events in anaesthesia (Fletcher et al. 2002; Gwinnutt and Gwinnutt, 2016). The provision of perioperative care requires distinct, yet overlapping non-technical skills. In the context of anaesthesia assistance, these include communication, situational awareness, teamwork, decision making and leadership (Rutherford et al., 2012). Students identified the development of leadership, communication and teamwork skills during their preparation and participation in the debate. These skills have been identified in other studies that also sought to assess the value of debate in education. Other non-technical skills included coping with pressure and being able to plan and prepare—all of which have significant value in the perioperative setting (Flin, 2013). Other studies exploring the use of debate in nursing, medical and pharmacy education have identified skill development in some of these areas, albeit without explicitly connecting them to non-technical skills (Doody and Condon, 2012; Hanna et al., 2014; Hartin et al., 2017; Latif et al., 2018). For instance, encouraging teamwork (Hanna et al., 2014), promoting leadership (Hartin et al., 2017) and improving communication (Latif et al., 2018).

In many respects, the debate encouraged the use of the kinds of non-technical skills that are recognised to have utility in the perioperative and wider healthcare context. This study provides support for debates being considered as an additional means of supporting the development of non-technical skills during undergraduate allied health and nursing education. This is significant because deficiencies in non-technical skills are a well-known contributory factor in errors and serious adverse incidents, and so this finding warrants further study and discussion (Flin et al., 2010; Luoma and Wilson, 2014; Schulz et al., 2016). 
As outlined in the third theme, a deep learning approach in contrast to surface learning was identified. A deep learning approach to learning describes where students meaningfully engage with the subject content and treat it as something worthy of investing time to understand (Biggs and Tang, 2007). Treating the content as meaningful requires a student to engage in higher-level cognitive activity that is orientated towards trying to understand and critically analyse new ideas (Hall, 2011; Dolmans et al., 2016). Findings in this study indicate that the debate encouraged students to engage in higher-order cognitive activity indicative of a deep approach to learning, and wanting to understand the intricacies and nuances of the topic. This is congruent with the findings from previous research (Scott, 2008; Doody and Condon, 2012; Yang and Rusli, 2012; Boucaud et al., 2013; Alén et al., 2015; Mumtaz and Latif, 2017). Preparation and participation in a debate provide an opportunity and space for students to exercise higher-order thinking skills that are are not easily developed within a traditional lecture format. However, there are other contributory factors that might explain student's willingness to engage with this approach to learning. For example, the topic of the debate was organ donation, and students may therefore have had an interest in understanding the current legislation, the proposed changes and the ethical questions associated with it. This explanation would indicate that the topic of debate could affect how students meaningfully engage with the debate method itself (Oros, 2007). Students were also required to debate with and in front of their peers and so they also had an interest in being informed enough to engage in critical discussion.

\section{Study limitations}


First, with respect to non-technical skills, this study only identifies their perceived development and therefore did not attempt to identify any measurable improvement. Whether the use of debates can lead to a measurable short or long-term improvement in certain non-technical skills is outside the scope of this study. Second, whether students who demonstrated an increased openness materialised into a long-term commitment to value viewpoint diversity would require further research. Third, debates do not always incorporate a cross-examination component and so the findings may only be representative of the outcomes of the structure and time allocated to prepare for this kind of debate and those like it.

\section{Conclusions}

The findings from this study suggest that debate can be a valuable pedagogical tool to incorporate into nursing and allied health education. Engaging in debate encourages students to critically reflect on their assumptions and beliefs on controversial ethical topics - in some cases leading them to rethink their original position. Debate also cultivates meaningful engagement with a topic and can encourage the use and development of higher-order cognitive skills. Preparation and participation for a debate encourages critical thinking and the development of non-technical skills that have utility in the academic and clinical contexts. Future research should consider the use of debate to develop salient non-technical skills relevant in clinical practice.

\section{Declaration of interest}

None. 


\section{References}

1. Agha RA, Fowler AJ, Sevdalis N. 2015. The role of non-technical skills in surgery. Ann Med Surg (Lond). 4(4):422-27. https://doi.org/10.1016/j.amsu.2015.10.006.

2. Alén E, Domínguez T, De Carlos P. 2015. University students' perceptions of the use of academic debates as a teaching methodology. J Hosp Leis Sport Tour Educ.

16:15-21. https://doi.org/10.1016/j.jhlste.2014.11.001.

3. Arrue M, Unanue S, Merida D. 2017. Guided university debate: Effect of a new teaching-learning strategy for undergraduate nursing students. Nurse Educ Today. 59:26-32. https://doi.org/10.1016/j.nedt.2017.08.011

4. Austin CL, Saylor R, Finley PJ. 2017. Moral distress in physicians and nurses: impact on professional quality of life and turnover. Psychol Trauma. 9(4):399-406. http://dx.doi.org/10.1037/tra0000201.

5. Biggs J, Tang C. 2007. Teaching for quality learning at university. $3^{\text {rd }}$ ed. Maidenhead: Open University Press.

6. Bloom B, Englehart M, Furst E, Hill W, Krathwohl D. 1956. Taxonomy of educational objectives: The classification of educational goals. Handbook I: Cognitive domain. New York, NY: David McKay Company.

7. Boucaud DW, Nabel M, Eggers CH. 2013. Oxford-style debates in a microbiology course for majors: a method for delivering content and engaging critical thinking skills. J Microbiol Biol Educ. 14(1):2-11. http://dx.doi.org/10.1128/jmbe.v14i1.433

8. Braun V, Clarke V. 2006. Using thematic analysis in psychology. Qual Res Psychol. 3(2):77-101. 
9. Brazil K, Kassalainen S, Ploeg J, Marshall D. 2010. Moral distress experienced by health care professionals who provide home-based palliative care. Soc Sci Med. 71(9):1687-91. https://doi.org/10.1016/j.socscimed.2010.07.032.

10. Candela L, Michael SR, Mitchell S. 2003. Ethical debates: enhancing critical thinking in nursing students. Nurse Educ. 28(1):37-39

11. Carter P, Jarman B. 2013. Who knew what, and when, at Mid Staffs? BMJ. 346: f726. https://doi.org/10.1136/bmj.f726

12. Chadwick R, Gallagher A. 2016. Ethics and Nursing Practice. $2^{\text {nd }}$ ed. London: Palgrave.

13. Choe K, Park S, Yoo SY. 2014. Effects of constructivist teaching methods on bioethics education for nursing students: a quasi-experimental study. Nurse Educ Today. 34(5): 848-853. https://doi.org/10.1016/j.nedt.2013.09.012.

14. Department of Health and Social Care. 2017. Introducing 'opt-out' consent for organ and tissue donation in England.

https://www.gov.uk/government/consultations/introducing-opt-out-consent-for-organand-tissue-donation-in-england [accessed 25 March 2019.]

15. Dolmans DHJM, Loyens SMM, Marcq H, Gijbels D. 2016. Deep and surface learning in problem-based learning: a review of the literature. Adv Health Sci Educ Theory Pract. 21(5):1087-1112. https://doi.org/10.1007/s10459-015-9645-6.

16. Doody O, Condon M. 2012. Increasing student involvement and learning through using debate as an assessment. Nurse Educ Pract. 12(4):232-237. https://doi.org/10.1016/j.nepr.2012.03.002. 
17. Fletcher GCL, McGeorge P, Flin R, Glavin RJ, Maran NJ. 2002. The role of non-technical skills in anaesthesia: a review of current literature. Br J Anaesth. 88(3):418-429. https://doi.org/10.1093/bja/88.3.418.

18. Flin R, O’Connor P, Crichton M. 2008. Safety at the Sharp End: A Guide to Non-Technical Skills. Aldershot: Ashgate.

19. Flin R, Patey R, Glavin R, Maran N. 2010. Anaesthetists' non-technical skills. Br J Anaesth. 105(1):38-44. https://doi.org/10.1093/bja/aeq134.

20. Flin R. 2013. Non-technical skills for anaesthetists, surgeons and scrub practitioners (ANTS, NOTTS and SPLINTS). The Healthcare Foundation. 1-9.

21. Francis R. 2013. Report of the Mid Staffordshire NHS Foundation Trust public inquiry. London: The Stationery Office.

https://www.gov.uk/government/publications/report-of-the-mid-staffordshire-nhs-fou ndation-trust-public-inquiry

22. Goodman, C, Evans, C. 2010. Focus Groups, in: Gerrish, K., Lacey, A. (Eds.), The Research Process in Nursing. 6th ed. Oxford: Wiley-Blackwell, pp. 358-368.

23. Gwinnutt M, Gwinnutt CL. 2016. Clinical Anaesthesia: Lecture notes. $5^{\text {th }}$ ed. Oxford: Wiley-Blackwell.

24. Hall, D. 2011. Debate: Innovative Teaching to Enhance Critical Thinking and Communication Skills in Healthcare Professionals. The Internet Journal of Allied Health Sciences and Practice. 9(3):7.

25. Hanna LA, Barry J, Donnelly R et al. 2014. Using Debate to Teach Pharmacy Students About Ethical Issues. Am J Pharm Educ. 78(3):57. https://doi.org/10.5688/ajpe78357. 
26. Hartin P, Birks M, Bodak M, Woods C, Hitchins M. 2017. A debate about the merits of debate in nurse education. Nurse Educ Pract. 26:118-120. https://doi.org/10.1016/j.nepr.2017.08.005.

27. Health and Care Professions Council (HCPC). Guidance on conduct and ethics for students. 2016.

http://www.hpc-uk.org/assets/documents/10002C16Guidanceonconductandethicsforst udents.pdf [accessed 26 November 2018.]

28. Huryn JS. 1986. Debating as a Teaching Technique. Teach Sociol. 14(4):266-269. https://doi.org/10.2307/1318385.

29. Kennedy R. 2007. In-Class Debates: Fertile Ground for Active Learning and the Cultivation of Critical Thinking and Oral Communication Skills. International Journal of Teaching and Learning in Higher Education. 19(2):183-190.

30. Kennedy R. 2009. The power of in-class debates. Active Learning in Higher Education. 10(3):225-236. https://doi.org/10.1177/1469787409343186.

31. Keynejad RC, Creed S, Fernando M, Bell D, Codling D, Crowther G, Harrison JR, Jaleel S, Kendall K, Megahey L, Noble E, O’Donnell C, Pilcher F, Walker T, and McLaughlan, D. 2017. Docbate: A National Medical Student Debate. Acad Psychiatry. 41(6):839-841. https://doi.org/10.1007/s40596-017-0697-1.

32. Koklanaris N, MacKenzie AP , Fino ME, Arslan AA, Seubert DE. 2008. Debate preparation/participation: an active, effective learning tool. Teach Learn Med. 20(3):235-238. https://doi.org/10.1080/10401330802199534.

33. Kulju K, Stolt M, Suhonen R, Leino-Kilpi H. 2016. Ethical competence: A concept analysis. Nurs Ethics. 23(4):401-412. https://doi.org/10.1177/0969733014567025. 
34. Latif R, Mumtaz S, Mumtaz R, Hussain A. 2018. A comparison of debate and role play in enhancing critical thinking and communication skills of medical students during problem based learning. Biochem Mol Biol Educ. 46(4):336-342. https://doi.org/10.1002/bmb.21124.

35. Lilienfeld SO, Lynn SJ. 2014. Errors/Biases in Clinical Decision Making, in: Cautin RL, Lilienfeld SO (Eds.), The Encyclopedia of Clinical Psychology. https://doi.org/10.1002/9781118625392.wbecp567

36. Luoma AMV, Wilson SR. 2014. Clinical risk management for anaesthetists. Contin Educ Anaesth Crit Care Pain. 15(1):14-19. https://doi.org/10.1093/bjaceaccp/mku003. 37. Mason, J. 2017. Qualitative Researching. 3rd ed. London: SAGE.

38. McCarthy J. 2013. Nursing ethics and moral distress: the story so far. [accessed 2018 Nov 26]. Nurs Ethics. http://journals.sagepub.com/pb-assets/cmscontent/NEJ/NEJ-suppl-Moral-distress.pdf.

39. Monrouxe LV, Rees CE, Dennis I, et al. 2015. Professionalism dilemmas, moral distress and the healthcare student: insights from two online UK-wide questionnaire studies. BMJ Open. 5:e007518. http://dx.doi.org/10.1136/bmjopen-2014-007518.

40. Morley G, Ives J, Bradbury-Jones C et al. 2019. What is 'moral distress'? A narrative synthesis of the literature. Nurs Ethics. 26(3):646-662. https://doi.org/10.1177/0969733017724354.

41. Mumtaz S, Latif R. 2017. Learning through debate during problem-based learning: an active learning strategy. Adv Physiol Educ. 41(3):390-394. https://doi.org/10.1152/advan.00157.2016.

42. Nickerson RS. 1998. Confirmation Bias: A Ubiquitous Phenomenon in Many Guises. Rev Gen Psychol. 2(2):175-220. http://dx.doi.org/10.1037/1089-2680.2.2.175. 
43. Nursing and Midwifery Council. The Code: Professional standards of practice and behaviour for nurses, midwives and nursing associates. 2018. https://www.nmc.org.uk/globalassets/sitedocuments/nmc-publications/nmc-code.pdf [accessed 26 March 2019.]

44. Onen D. 2016. Debate to Teach: A Multi-skilling Pedagogy Often Neglected by University Academic Staff. International Journal of Learning, Teaching and Educational Research. 15(7):110-126.

45. Oros AL. 2007. Let's Debate: Active Learning Encourages Student Participation and Critical Thinking. Journal of Political Science Education. 3(3):293-311. https://doi.org/10.1080/15512160701558273.

46. Peasah SK, Marshall LL. 2017. The use of debates as an active learning tool in a college of pharmacy healthcare delivery course. Curr Pharm Teach Learn. 9(3):433-440. https://doi.org/10.1016/j.cptl.2017.01.012.

47. Penny NH, Ewing TL, Hamid RC et al. 2014. An investigation of moral distress experienced by occupational therapists. Occup Ther Health Care. 28(4):382-393. https://doi.org/10.3109/07380577.2014.933380.

48. Robichaux K. 2016. Ethical competence in nursing practice. Competencies, skills, decision making. New York, NY: Springer Publishing Company.

49. Rodger D, Mahoney C. From healthcare assistant to student operating department practitioner-are you ready for the ODP challenge? British Journal of Healthcare Assistants. 11(5):248-251. https://doi.org/10.12968/bjha.2017.11.5.248

50. Rutherford JS, Flin R, Mitchell L. 2012. Non-technical skills of anaesthetic assistants in the perioperative period: a literature review. Br J Anaesth. 109(1):27-31. https://doi.org/10.1093/bja/aes125. 
51. Schaefer R, Vieira M. 2015. Ethical competence as a coping resource for moral distress in nursing. Texto Contexto Enferm. 24(2):563-573. http://dx.doi.org/10.1590/0104-07072015001032014.

52. Schulz CM, Krautheim V, Hackemann A et al. 2016. Situation awareness errors in anesthesia and critical care in 200 cases of a critical incident reporting system. BMC Anesthesiol. 16:4. https://doi.org/10.1186/s12871-016-0172-7.

53. Scott S. 2008. Perceptions of Students' Learning Critical Thinking through Debate in a Technology Classroom: A Case Study. Journal of Technology Studies. 7(1):39-44.

54. Seeleman C, Suurmond J, Stronks K. 2009. Cultural competence: A conceptual framework for teaching and learning. Med Educ. 43(3):229- 237. https://doi.org/10.1111/j.1365-2923.2008.03269.x.

55. Snider A, Schnurer M. 2006. Many Sides: Debate Across the Curriculum. New York, NY: Idebate Press.

56. Stewart-Lord A, Ahmed S, Aldridge L et al. 2011. Debating the use of Arc therapy and Tomotherapy. Synergy: imaging and therapy practice. $28-30$.

57. Talbot M. 2012. Bioethics: An Introduction. Cambridge: Cambridge University Press.

58. Vo HX, Morris RL. 2006. Debate as a Tool in Teaching Economics: Rationale, Technique, and Some Evidence. Journal of Education for Business. 81(6):315-320. https://doi.org/10.3200/JOEB.81.6.315-320.

59. Wacker J, Kolbe M. 2014. Leadership and teamwork in anesthesia - Making use of human factors to improve clinical performance. Trends in Anaesthesia and Critical Care. 4(6):200-205. https://doi.org/10.1016/j.tacc.2014.09.002. 
60. Willsher KA. 2013. The legacy of "Joanna": The role of ethical debate in nurse preparation. Nurse Educ Today. 333(4):384-387.

https://doi.org/10.1016/j.nedt.2013.01.019.

61. Yang CH, Rusli E. 2012. Using Debate As A Pedagogical Tool In Enhancing Pre-Service Teachers Learning And Critical Thinking. Journal of International Education Research. 8(2):135-144. https://doi.org/10.19030/jier.v8i2.6833. 


\section{Figure. 1. A description of the debate format.}

1) Opening statements (2 minutes each): Defines the motion and briefly explains why they are for or against the motion.
a) Pro side
b) Con side

2) Main arguments (15 minutes each): Team members present their arguments for or against the motion.
a) Pro side
b) Con side

3) Preparation time (10 minutes): Both teams get additional time to prepare their rebuttal and a maximum of four questions to ask the opposite team.

a) Both sides

4) Rebuttal (15 minutes each): Each team will present their rebuttal and ask a maximum of four questions to the opposing team. The opposing team gets one minute to respond to each question.
a) Pro side
b) Con side

5) Closing statements (2 minutes each): Each team will summarise their main arguments and explain why they think they have won the debate.
a) Pro side 